\title{
sciendo
}

\section{Acute Effects of Barefoot And Minimalist Footwear on Medial Tibiofemoral Compartment Loading During Running: A Statistical Parametric Mapping Approach}

\author{
by \\ Jonathan Sinclair ${ }^{1}$, Bobbie Butters ${ }^{1}$, Philip Stainton ${ }^{1}$
}

\begin{abstract}
The current investigation examined the effects of running barefoot and in minimalist footwear on medial tibiofemoral compartment loading, compared to conventional running trainers. Fifteen male runners ran over a force platform in five different footwear conditions (barefoot, Vibram five-fingers (Footwear A), Inov-8 (Footwear B) NikeFree (Footwear $C$ ), and running trainer) whilst lower extremity kinematics were examined using a three-dimensional camera system. Medial compartment loading during the stance phase was explored using the knee adduction moment (KAM). In addition, the KAM instantaneous load rate was also calculated. Differences between footwear across the entire stance phase were examined using 1-dimensional statistical parametric mapping, whereas differences in discrete parameters were explored using one-way repeated measures ANOVA. Statistical parametric mapping revealed that Footwear B was associated with a significantly larger KAM compared to the running trainer from 15-20 and 25-30\% of the stance phase and also Footwear C from 15-20\% of the stance phase. The KAM instantaneous load rate was significantly larger in the barefoot $(210.69 \mathrm{Nm} / \mathrm{kg} / \mathrm{s})$, Footwear A $(200.23 \mathrm{Nm} / \mathrm{kg} / \mathrm{s})$ and Footwear B $(186.03 \mathrm{Nm} / \mathrm{kg} / \mathrm{s})$ conditions in comparison to Footwear $C(100.88 \mathrm{Nm} / \mathrm{kg} / \mathrm{s})$ and running trainers $(92.70 \mathrm{Nm} / \mathrm{kg} / \mathrm{s})$. The findings from this study indicate that running barefoot and in minimalist footwear with the least midsole interface may place runners at increased risk of medial compartment knee $O A$, although further exploration using habitual barefoot / minimalist footwear users is required.
\end{abstract}

Key words: biomechanics, footwear, running, knee, overuse injury.

\section{Introduction}

Running is associated with an array of physiological benefits; however, runners are renowned for their susceptibility to chronic pathologies (Taunton et al., 2002). As many as $80 \%$ of runners will experience a chronic injury every year (van Gent et al., 2007).

The knee joint is the most susceptible musculoskeletal structure to chronic pathologies in runners (van Gent et al., 2007). Tibiofemoral pathologies account for up to $16.8 \%$ of all knee injuries (Taunton et al., 2002) and the initiation of knee osteoarthritis (OA) is mediated by mechanical stimuli (Brandt et al., 2008). The pathogenesis of tibiofemoral overuse injuries relates to the magnitude and frequency of the loads experienced by the joint during running, which represent the initiating mechanism that causes the onset of knee OA (Miyazaki et al., 2002). The medial aspect of the tibiofemoral joint is significantly more susceptible to injury than the lateral compartment (Wise et al., 2012). Contact loading at the tibiofemoral joint is mediated via the knee adduction moment (KAM). The KAM is frequently utilized as a pseudo measure of medial tibiofmeoral contact loading (Birmingham et al., 2007; Kumar et al., 2017; Lynn et al., 2007), and the peak KAM as well as the loading rate of the KAM have been cited as important predictors of radiographic knee OA (Miyazaki et al., 2002; Morgenroth et al., 2014).

1 - Centre for Applied Sport \& Exercise Sciences, University of Central Lancashire, Lancashire, UK. 
Given their prevalence and debilitating nature, numerous strategies have been investigated in clinical research, in an attempt to attenuate the risk of knee pathologies in runners. Barefoot running has received significant attention in biomechanical literature; based on the proposition that running without shoes may be associated with a reduced incidence of chronic pathologies (Lieberman et al., 2010). The popularity of barefoot running lead has led to the introduction of minimalist footwear, designed to transfer the prospective benefits of running barefoot into a shod condition. Previous analyses in relation to the knee joint have shown unequivocally that running barefoot and in minimalist footwear attenuates the loads experienced by the patellofemoral joint (Bonacci et al., 2014; Sinclair, 2014; Sinclair et al., 2016). However, there has yet to be any published investigation exploring the effects of running barefoot / in minimalist footwear on medial tibiofemoral compartment loading.

Therefore, the aim of the current investigation was to examine the effects of running barefoot and in minimalist footwear on medial compartment loading during the stance phase, in relation to conventional running trainers. This was explored predominantly using an innovative statistical procedure known as statistical parametric mapping (SPM), whereby statistical differences between footwear were explored across the entire stance phase as opposed to at individual discrete time points. An investigation of this nature may provide important information regarding the most appropriate footwear for runners susceptible to medial compartment knee OA.

\section{Methods}

\section{Participants}

Fifteen healthy male runners (age $25.30 \pm$ 4.69 years, body height $1.78 \pm 0.10 \mathrm{~m}$ and body mass $71.34 \pm 5.82 \mathrm{~kg}$ ) volunteered to take part in this study. Participants were identified as recreational runners, who trained a minimum of 3 times/week completing a minimum of 35 $\mathrm{km} /$ week. Pilot analyses showed that all runners exhibited a habitual rearfoot strike pattern, as they demonstrated an impact peak in their vertical ground reaction force curve, when running in their own footwear. The participants provided written informed consent and the procedure was approved by an institutional ethical panel.

\section{Experiential footwear}

Footwear examined in this study consisted of a running trainer (New Balance 1260 v2), Vibram five-fingers (M108 Classic Henceforth termed Footwear A), Inov-8 (Evoskin - Henceforth termed Footwear B) and Nike-Free (5.0 - Henceforth termed Footwear C) in sizes 810 men's UK (Figure 1). The running trainer had a mean mass of $0.285 \mathrm{~kg}$, heel thickness of $25 \mathrm{~mm}$ and heel drop of $14 \mathrm{~mm}$, Footwear A an average mass of $0.167 \mathrm{~kg}$, heel thickness of $7 \mathrm{~mm}$ and a heel drop of $0 \mathrm{~mm}$, Footwear B an average mass of $0.100 \mathrm{~kg}$, heel thickness of $4 \mathrm{~mm}$ and a heel drop of $0 \mathrm{~mm}$ and Footwear $\mathrm{C}$ an average mass of $0.240 \mathrm{~kg}$, heel thickness of $23 \mathrm{~mm}$ and a heel drop of $13 \mathrm{~mm}$

\section{Procedures}

Participants ran at $4.0 \mathrm{~m} / \mathrm{s} \pm 5 \%$, striking a piezoelectric force platform (Kistler, Kistler Instruments Ltd) with their right (dominant) foot. Running velocity was monitored using infrared timing gates (Newtest, Oy Finland). The stance phase was delineated as the duration over which $>20 \mathrm{~N}$ vertical force was applied to the force platform. Runners completed five successful trials in each footwear condition in a counterbalanced manner. Kinematic data was captured at $250 \mathrm{~Hz}$ via an eight camera motion capture system (Qualisys Medical AB, Goteburg, Sweden).

Lower extremity segments were modelled in 6 degrees of freedom using the calibrated anatomical systems technique (Cappozzo et al., 1995). Lower extremity segments were delineated in accordance with those of Sinclair (2014). Static calibration trials were obtained in each footwear allowing the anatomical markers to be referenced in relation to the tracking markers/clusters.

\section{Processing}

Dynamic trials were digitized using Qualisys Track Manager then exported as C3D files to Visual 3D (C-Motion, Germantown, USA). Ground reaction force and kinematic data were smoothed using cut-off frequencies of 50 and 12 $\mathrm{Hz}$ with a low-pass Butterworth 4th order zerolag filter (Sinclair, 2014). Knee joint kinetics were computed using Newton-Euler inverse-dynamics, allowing net knee joint moments to be calculated. Medial tibiofemoral compartment loading was 
examined using the KAM during the stance phase.

The KAM magnitude was normalized by dividing by body mass $(\mathrm{Nm} / \mathrm{kg})$. Following this KAM data for all participants in each footwear during the stance phase was extracted and time normalized to 101 data points. In addition, the KAM instantaneous load rate $(\mathrm{Nm} / \mathrm{kg} / \mathrm{s})$ was determined the maximum slope in the KAM computed between each frame.

\section{Statistical analyses}

Differences in the KAM across the entire stance phase were examined using 1-dimensional SPM with MATLAB 2017a (MATLAB, MathWorks, Natick, USA), in accordance with Pataky et al. (2016), using the source code available at http://www.spm1d.org/. In agreement with Pataky et al. (2013), SPM was implemented in a hierarchical manner, analogous to one-way ANOVA with post-hoc t-tests. Therefore, the entire data-set was examined first, and if statistical significance was reached then post-hoc tests were conducted on each component separately. For the KAM instantaneous load rate, descriptive statistics of means, standard deviations (SD) and 95\% confidence intervals ( $95 \%$ CI) were calculated for each footwear condition. Differences between footwear in the KAM instantaneous load rate were examined using one-way repeated measures ANOVA, following which post-hoc pairwise comparisons were employed in the instance of a significant main effect. Effect sizes were quantified, using partial eta ${ }^{2}\left(\mathrm{pq}^{2}\right)$ and contextualized using the following guidelines; very small $=0-0.1$, small $=$ $0.1-0.3$, moderate $=0.3-0.5$, large $=0.5-0.7$, very large $=0.7-0.9$ and distinct $=0.9-1.0$ (Hopkins, 1997). The alpha $(\alpha)$ level for statistical significance was set at the 0.05 level throughout. Statistical analysis of the KAM instantaneous load rate was undertaken using SPSS v24.0 (SPSS Inc, USA), and the minimum clinically important difference (MCID) for this measurement was considered to be $31.64 \mathrm{Nm} / \mathrm{kg} / \mathrm{s}(2.3 *$ the pooled standard error of this measurement) (Wyrwich, 2004).

\section{Results}

Figure 2 shows the KAM during the stance phase as a function of the experimental footwear. Figures 3-6 show the KAM compared between footwear across the stance phase using SPM. Table 1 presents differences in the KAM instantaneous load rate function of different footwear.

Statistical parametric mapping

The analysis of the overall data set using SPM revealed significant differences between conditions and thus post-hoc investigation between individual footwear was required (Figure 3). This revealed that the KAM was significantly larger $(p<0.001)$ during barefoot running in comparison to Footwear B, in the period from $75-85 \%$ of the stance phase (Figure $4 b)$. In addition, it was also shown that the KAM was significantly larger $(p<0.001)$ in Footwear $C$ in relation to the running trainer in the period from $20-25 \%$ of the stance phase (Figure 5a). Finally, the Footwear B was associated with a significantly larger KAM compared to the running trainer $(p=0.031 \& p=0.045)$ from $15-20$ and $25-30 \%$ of the stance phase (Figure $6 \mathrm{a}$ ) and also Footwear C ( $p=0.042)$ from $15-20 \%$ of the stance phase (Figure 6b).

KAM instantaneous load rate

A main effect $\left(p<0.05, \mathrm{p}^{2}=0.62\right)$ was also observed for the KAM instantaneous load rate. Post-hoc pairwise comparisons showed that the KAM instantaneous load rate was significantly larger in the barefoot $(p=0.0002 \& 0.0001)$, Footwear A $(p=0.000003 \& 0.000007)$ and Footwear B ( $p=0.00003 \& 0.00001)$ in comparison to Footwear $C$ and running trainer (Table 1).

\section{Discussion}

The aim of the current investigation was to explore the effects of running barefoot and in minimalist footwear on medial compartment loading compared to conventional running trainers using a SPM approach. To the authors knowledge this is the first quantitative examination of the effects of running barefoot and in minimalist footwear on medial tibiofemoral loading in relation to conventional running footwear.

Tibiofemoral pathologies are common chronic pathologies in runners (Taunton et al., 2002). Exploration of the KAM across the entire stance phase using SPM showed that Footwear B exhibited a significantly increased KAM at 15-20 and $25-30 \%$ of the stance phase, in relation to Footwear $\mathrm{C}$ and running trainers. 
Table 1

Knee adduction moment parameters (Mean, SD's \& 95\% CI) as a function of the different experimental footwear.

\begin{tabular}{|c|c|c|c|c|c|c|c|c|c|c|}
\cline { 2 - 9 } \multicolumn{1}{c|}{} & \multicolumn{2}{c|}{ Barefoot } & \multicolumn{2}{c|}{ Footwear A } & \multicolumn{2}{c|}{ Footwear B } & \multicolumn{2}{c|}{ Footwear C } & \multicolumn{2}{c|}{$\begin{array}{c}\text { Running } \\
\text { Trainer }\end{array}$} \\
\hline $\begin{array}{c}\text { KAM } \\
\text { instantaneous load } \\
\text { rate (Nm/kg/s) }\end{array}$ & $\begin{array}{c}210.69 \\
A B\end{array}$ & 84.90 & $\begin{array}{c}200.23 \\
A B\end{array}$ & 57.57 & $\begin{array}{c}186.03 \\
A B\end{array}$ & 62.11 & 100.88 & 38.81 & 92.70 & 23.03 \\
\hline
\end{tabular}

$M C I D=31.34 \mathrm{Nm} / \mathrm{kg} / \mathrm{s}$

$A=$ significantly different from Running Trainers

$B=$ significantly different from Footwear $C$
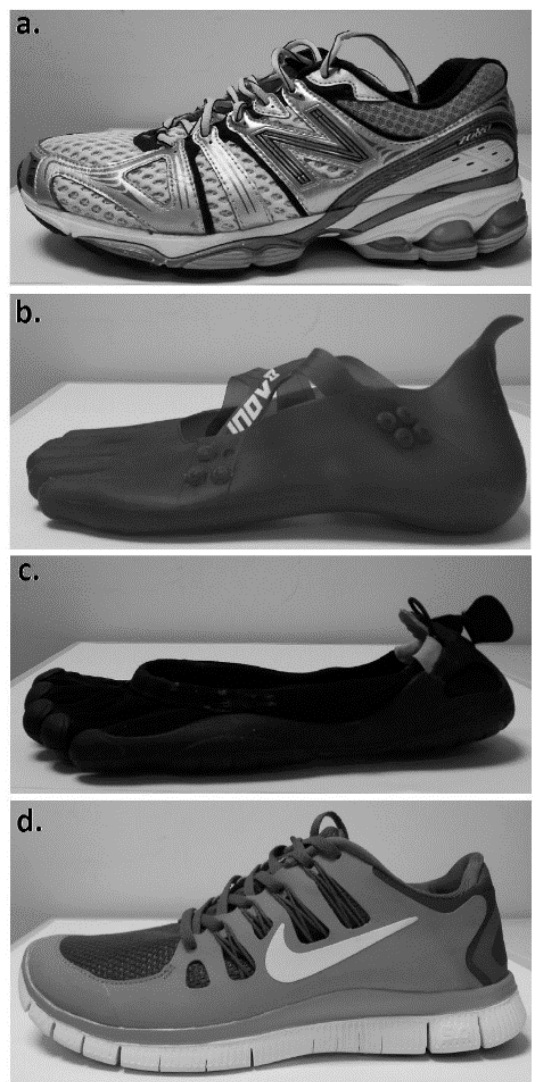

Figure 1

Experimental footwear ( $a$. = running trainer, $b .=$ Footwear $B, c .=$ Footwear $A$ \& d. $=$ Footwear $C$ ). 


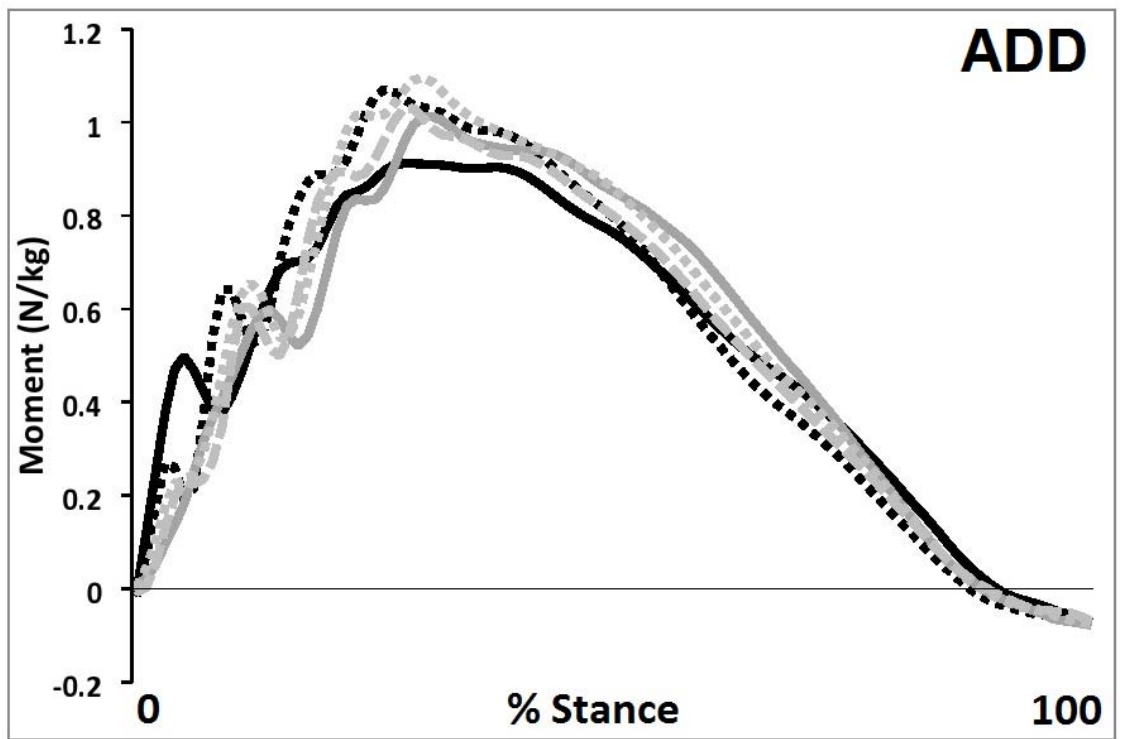

Figure 2

$K A M$ curves during the stance phase as a function of footwear (black = barefoot, grey $=$ running trainer, grey dash $=$ Footwear $A$, black dot $=$ Footwear $B$, grey dot $=$ Footwear $C),(A D D=$ adduction $)$.

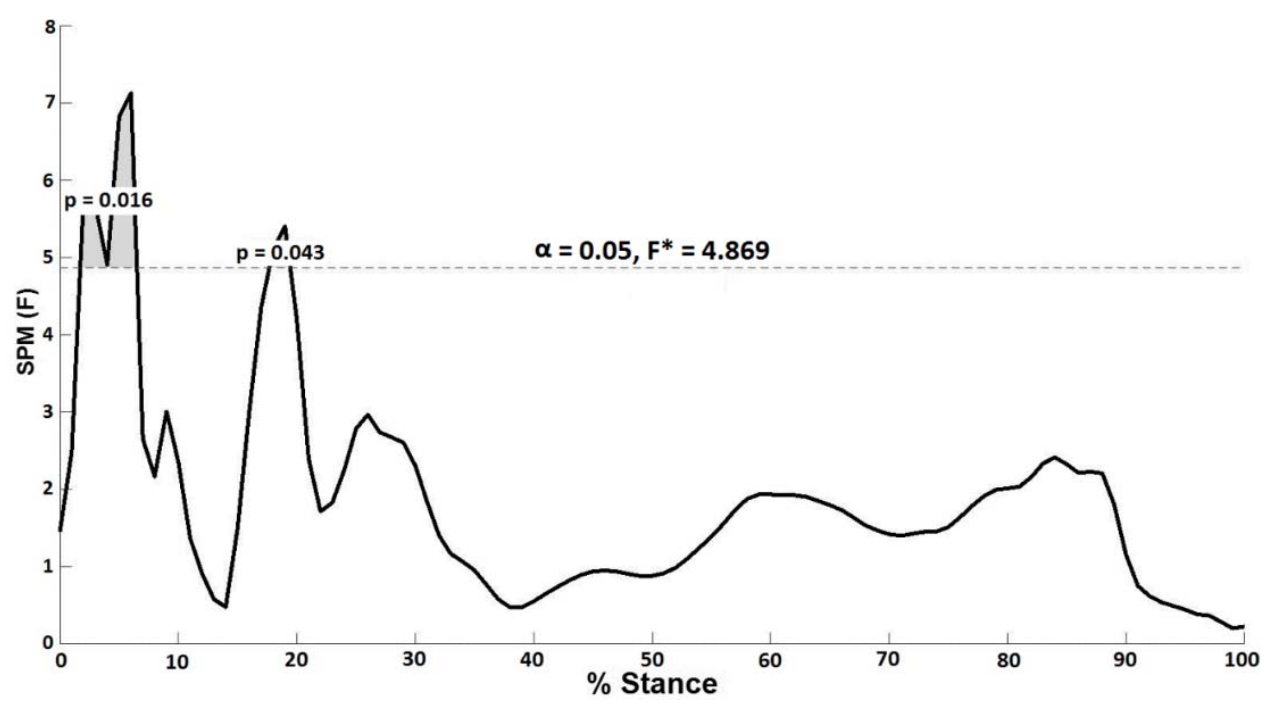

Figure 3

Comparison of the KAM across the stance phase in all footwear conditions. SPM (F) denotes the F value,

and critical thresholds for statistical significance are denoted via the horizontal dotted line. 

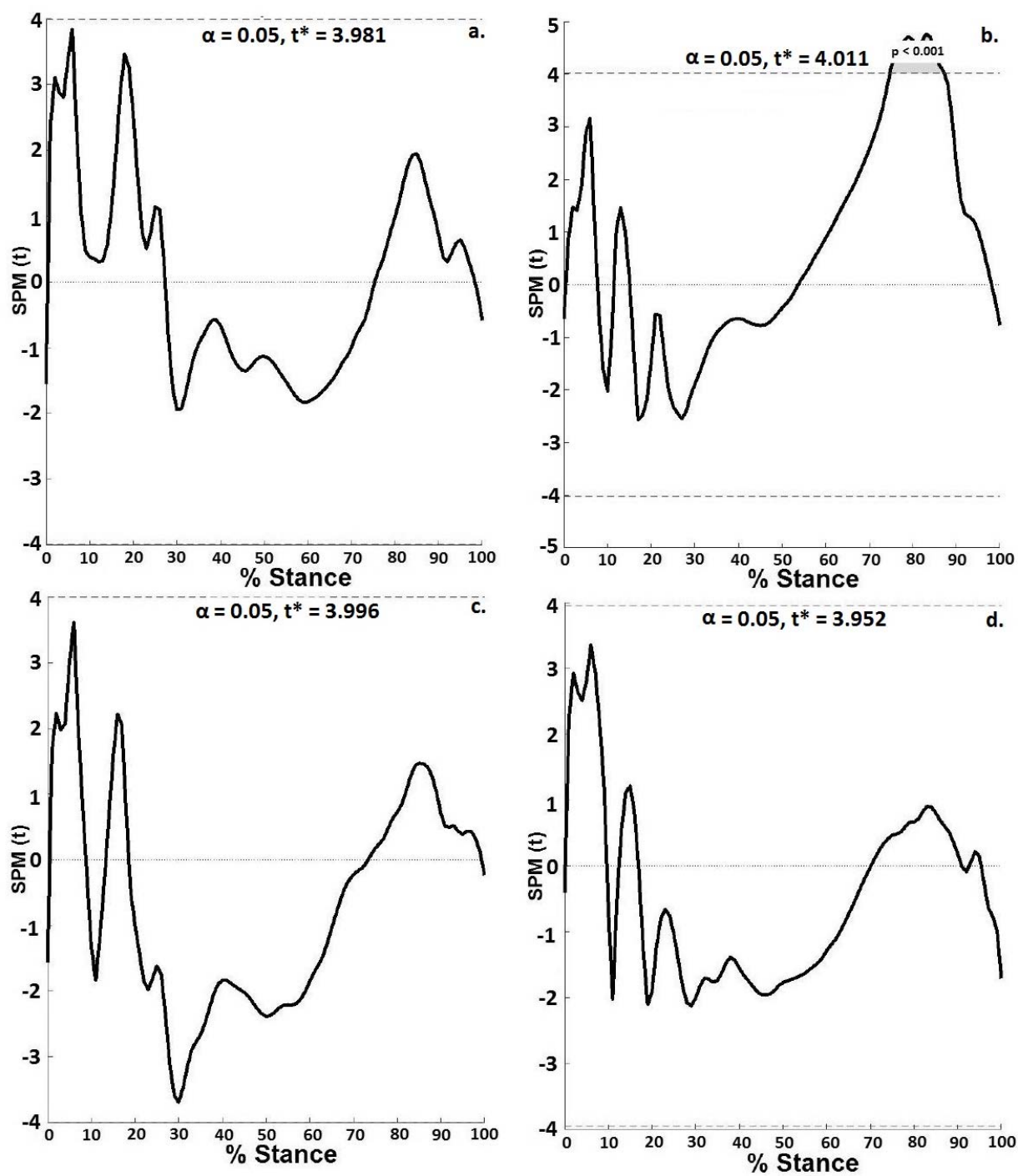

Figure 4

Comparison of the KAM across the stance phase, in barefoot vs. running trainer (a.), barefoot vs. Footwear B (b.), barefoot vs. Footwear $C$ (c.) barefoot vs. Footwear $A(d$.$) .$

Positive values indicate that the barefoot KAM values exceed those in the other footwear conditions;

SPM $(t)$ denotes the t value and critical thresholds for statistical significance are denoted via the horizontal dotted lines. 

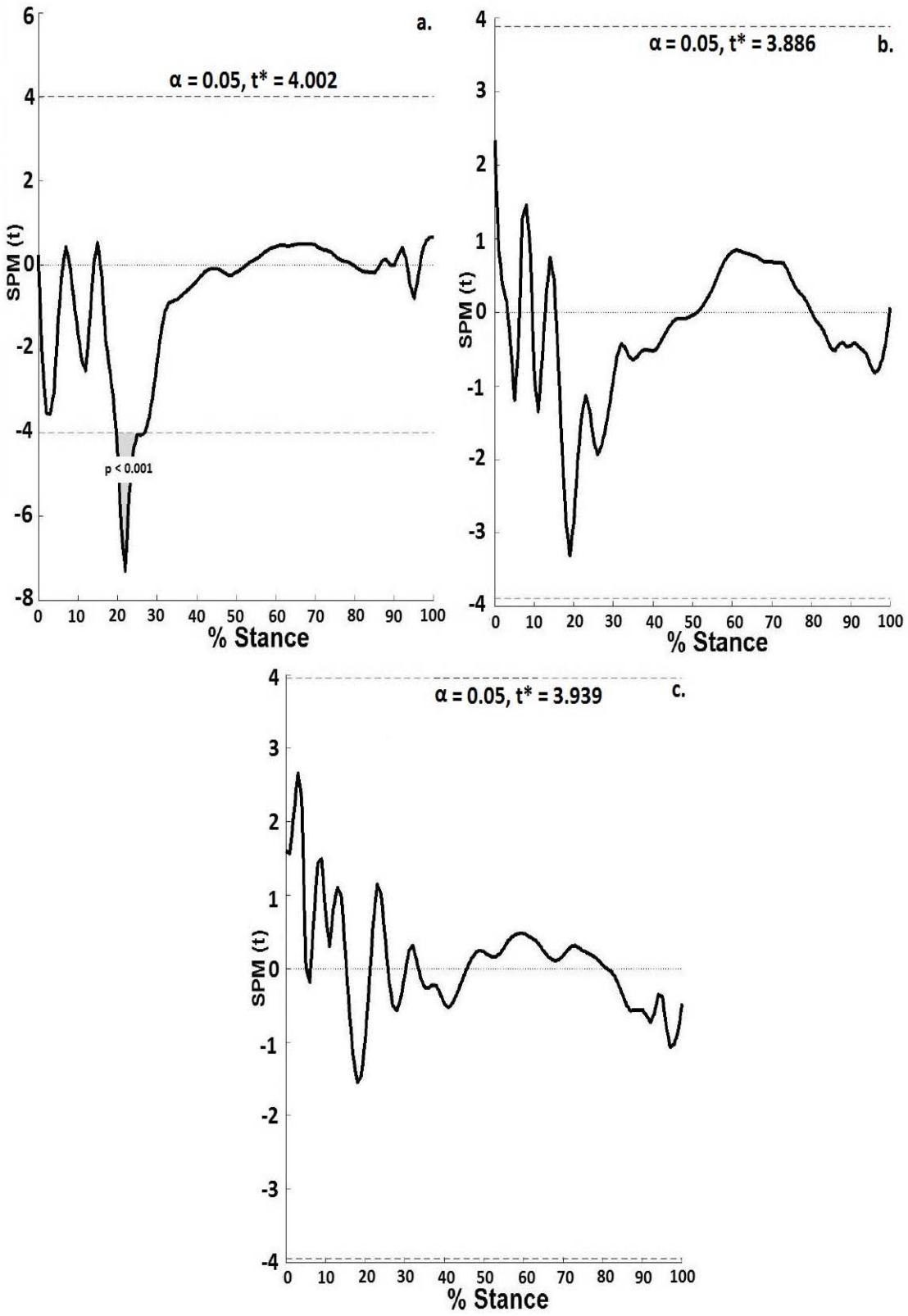

Figure 5

Comparison of the KAM across the stance phase, in running trainers vs. Footwear $C(a$.$) ,$ running trainers vs. Footwear A (b.) and Footwear $C$ vs. Footwear A (c.).

Positive values indicate that the running trainer / Footwear C KAM values exceed those in the other footwear conditions; SPM ( $t)$ denotes the tvalue and critical thresholds for statistical significance are denoted via the horizontal dotted lines. 

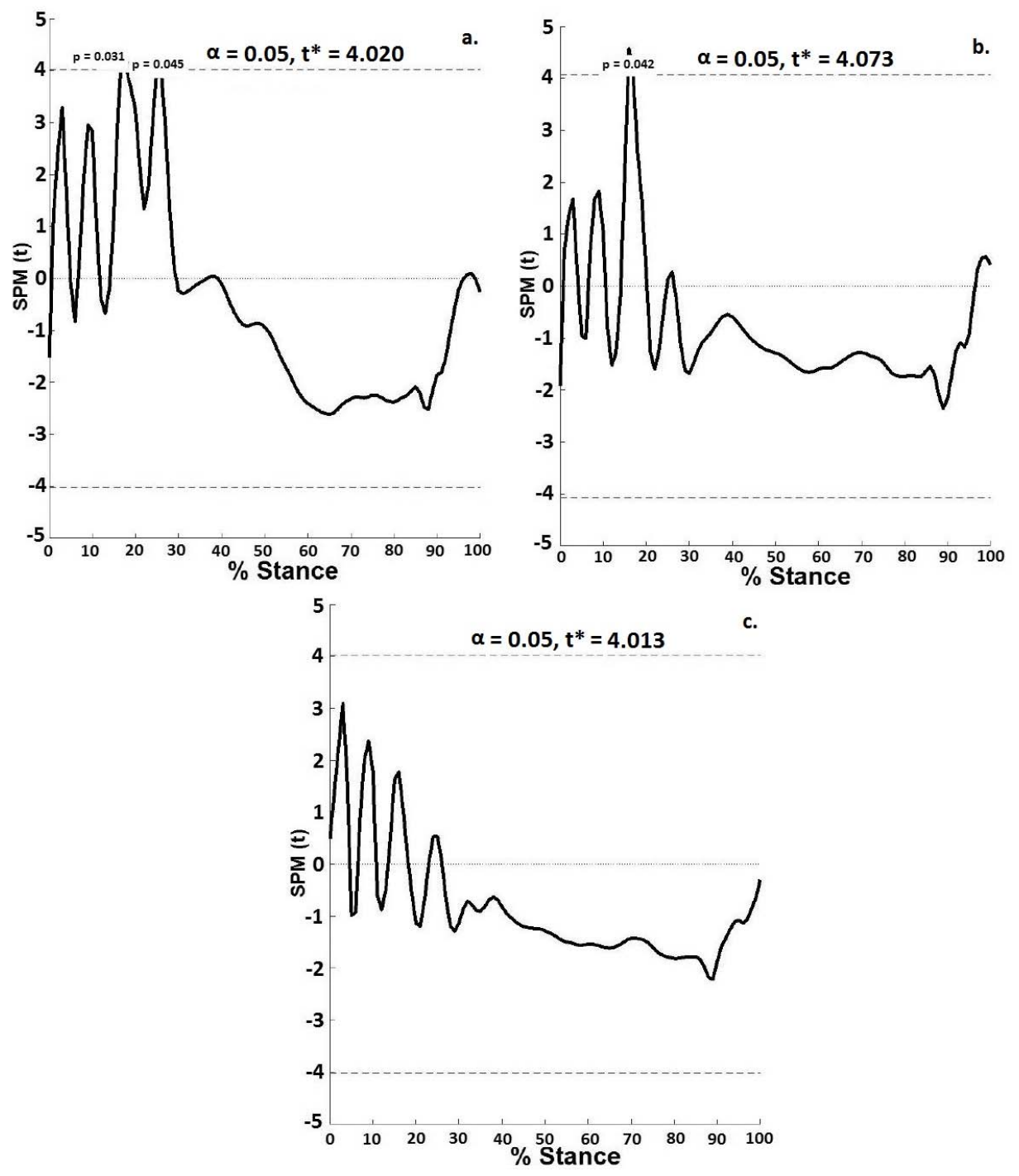

Figure 6

Comparison of the KAM across the stance phase, in Footwear B vs. running trainers (a.),

Footwear B vs. Footwear C (b.) and Footwear B vs. Footwear A (c.).

Positive values indicate that the Footwear B KAM values exceed those

in the other footwear conditions; SPM ( $t)$ denotes the t value and critical thresholds

for statistical significance are denoted via the horizontal dotted lines. 
This is an interesting observation that was likely caused by the peaks early in the KAM waveform, which were present in Footwear B (Figure 2). It is proposed that this is a reflection of the increased rate at which the ground reaction forces were experienced in Footwear B as Sinclair et al. (2013) showed that this footwear condition was associated with the highest rates of loading even compared to running barefoot. Given the proposed association between the magnitude of the KAM and chronic tibiofemoral pathologies (Birmingham et al., 2007), this indicates that Footwear B may place runners at increased risk during the early stance phase in relation to Footwear $\mathrm{C}$ and the running trainer condition.

In addition, the current investigation also revealed using SPM that the KAM was significantly larger in Footwear C, in relation to the running trainer from $20-25 \%$ of the stance phase. This is similarly a potentially important clinical observation as the KAM is strongly linked to the aetiology of chronic medial tibiofemoral pathologies (Birmingham et al., 2007). The current study therefore indicates that Footwear C may place runners at increased risk from tibiofemoral pathology during the early stance compared to the running trainer.

Importantly the current investigation also revealed that a statistically significant main effect with a large effect size was evident for the KAM instantaneous loading rate. Specifically, it was found that the KAM instantaneous rate of loading was significantly greater in the barefoot, Footwear A and Footwear B conditions. Importantly, it was also shown that the statistical differences between footwear exceeded the MCID. The KAM is an effective measure of compressive medial tibiofemoral compartment loading (Birmingham et al., 2007), and the KAM rate of loading is an important predictor of degenerative knee OA (Morgenroth et al., 2012). Thus it appears that running barefoot and in minimalist footwear with the least midsole interface may accentuate the risk of medial compartment knee OA in runners.
A limitation of the current investigation is that only the acute effects of running in different footwear were investigated. This limits the generalizability of the findings in relation to those who customarily run barefoot and in minimalist footwear, thus it is prudent for the current analysis to be repeated using a group of habitual barefoot / minimalist footwear users before a broad assertion regarding injury predisposition at the tibiofemoral joint can be drawn. A further potential drawback is that only male runners were examined. Female runners have been shown to exhibit distinct KAM profiles in relation to males (Sinclair and Selfe, 2015). Thus further exploration using a sample of female runners is a clear requirement for future analyses.

\section{Conclusion}

In conclusion, although the effects of barefoot and minimalist footwear have received extensive attention, current knowledge regarding differences in medial tibiofemoral loading when running these different kinds of footwear is lacking. Therefore, the current investigation contributes to the biomechanical literature base by exploring the KAM across the entire stance phase when running barefoot and in different minimalist footwear. The findings from this study using SPM importantly showed that Footwear B exhibited a significantly increased KAM during the early stance phase, in relation to Footwear C and running trainers. Furthermore, the KAM loading rate was found to be significantly larger when running barefoot and in minimalist footwear with the least midsole interface. This therefore indicates that these footwear conditions may place runners at increased risk of medial compartment knee OA, although further exploration using habitual barefoot / minimalist footwear users is required before a broader assertion regarding injury predisposition at the tibiofemoral joint can be drawn.

\section{Acknowledgements}

We thank Todd Pataky, Mark Robinson and Jos Vanrenterghem for their excellent website (http://www.spm1d.org/) and for generously providing the source code for this experiment.

\section{References}

Birmingham TB, Hunt MA, Jones IC, Jenkyn TR, Giffin JR. Test-retest reliability of the peak knee adduction moment during walking in patients with medial compartment knee osteoarthritis. Arthritis Care Res, 
2007; 57: 1012-1017

Bonacci J, Vicenzino B, Spratford W, Collins P. Take your shoes off to reduce patellofemoral joint stress during running. Br J Sports Med, 2014; 48: 425-428

Brandt KD, Dieppe P, Radin EL. Etiopathogenesis of osteoarthritis. Rheum Dis Clin North Am, 2008; 34: 531559

Cappozzo A, Catani F, Leardini A, Benedeti MG, Della CU. Position and orientation in space of bones during movement: Anatomical frame definition and determination. Clin Biomech, 1995; 10: 171-178

Hopkins WG. New view of statistics: Effect magnitudes. Retrieved 12 $2^{\text {th }}$ December, 2017 from http://www.sportsci.org/resource/stats/effectmag.html

Kumar D, Su F, Wu D, Pedoia V, Heitkamp L, Ma CB, Li X. Frontal Plane Knee Mechanics and Early Cartilage Degeneration in People With Anterior Cruciate Ligament Reconstruction: A Longitudinal Study. Am J Sports Med, 2017; (In press).

Lieberman DE, Venkadesan M, Werbel WA, Daoud AI, D'Andrea S, Davis IS, Mang'eni RO, Pitsiladis Y. Foot strike patterns and collision forces in habitually barefoot versus shod runners. Nature, 2010; 463: 531-535

Lynn SK, Reid SM, Costigan P. The influence of gait pattern on signs of knee osteoarthritis in older adults over a 5-11 year follow-up period: a case study analysis. The Knee, 2007; 14: 22-28.

Miyazaki T, Wada M, Kawahara H, Sato M, Baba H, Shimada S. Dynamic load at baseline can predict radiographic disease progression in medial compartment knee osteoarthritis. Ann Rheum Dis, 2002; 61: $617-622$

Morgenroth DC, Medverd JR, Seyedali M, Czerniecki JM. The relationship between knee joint loading rate during walking and degenerative changes on magnetic resonance imaging. Clin Biomech, 2014; 29: 664670

Pataky TC, Robinson MA, Vanrenterghem J. Vector field statistical analysis of kinematic and force trajectories. J Biomech, 2013; 46: 2394-2401

Pataky TC, Robinson MA, Vanrenterghem J. Region-of-interest analyses of one-dimensional biomechanical trajectories: bridging 0D and 1D theory, augmenting statistical power. Peer J, 2016; 4: 2652-2664

Sinclair J, Hobbs SJ, Currigan G, Taylor PJ. A comparison of several barefoot inspired footwear models in relation to barefoot and conventional running footwear. Comp Exerc Physiol, 2013; 9: 13-21

Sinclair J. Effects of barefoot and barefoot inspired footwear on knee and ankle loading during running. Clin Biomech, 2014; 29: 395-399

Sinclair J, Richards J, Selfe J, Fau-Goodwin J, Shore H. The influence of minimalist and maximalist footwear on patellofemoral kinetics during running. J App Biomech, 2016; 32: 359-364

Sinclair J, Selfe J. Sex differences in knee loading in recreational runners. J Biomech, 2015; 48: 2171-2175

Taunton JE, Ryan MB, Clement DB, McKenzie DC, Lloyd-Smith DR, Zumbo BD. A retrospective case-control analysis of 2002 running injuries. Br J Sports Med, 2002; 36: 95-101

van Gent RN, Siem D, van Middelkoop M, van Os AG, Bierma-Zeinstra SMA, Koes BW. Incidence and determinants of lower extremity running injuries in long distance runners: a systematic review. $\mathrm{Br} \mathrm{J}$ Sports Med, 2007; 41: 469-480

Wyrwich KW. Minimal important difference thresholds and the standard error of measurement: is there a connection?. J Biopharm Stat, 2004; 14: 97-110.

Wise BL, Niu J, Yang M, Lane NE, Harvey W, Felson DT, Lewis CE. Patterns of compartment involvement in tibiofemoral osteoarthritis in men and women and in whites and African Americans. Arthritis Care Res, 2012; 6: 847-852

\section{Corresponding author:}

\section{Dr. Jonathan Sinclair}

Centre for Applied Sport \& Exercise Sciences

Faculty of Health and Wellbeing

University of Central Lancashire; Preston; Lancashire; PR1 2HE 